\title{
Effect of Five Lubricants on Root Canal Walls during the Impression Phase of an Endodontic Post
}

\author{
Jorge Paredes Vieyra ${ }^{1^{*}}$, Julieta Acosta Guardado ${ }^{2}$, Javier Jimenez Enriquez ${ }^{3}$ and Miguel Alberto Zamudio Gomez ${ }^{4}$ \\ ${ }^{1}$ Department of Endodontics and Pediatric Dentistry, School of Dentistry, Autanoma University of California, Tijuana, Mexico \\ ${ }^{2}$ Private Practice in Endodontics, Mexican association of Endodontics, California, USA \\ ${ }^{3}$ Department of Oral Surgery and Pediatric Dentistry, School of Dentistry, Autanoma University of California, Tijuana, Mexico \\ ${ }^{4}$ Department of Pediatric Dentistry and Epidemiology, School of Dentistry, Autanoma University of California, Tijuana, Mexico
}

*Corresponding author: Dr. Jorge Paredes Vieyra, D.D.S, M.Sc., PhD., PMB \#1513, 710 ESan Ysidro Blvd., suite A, San Ysidro, California-92173, USA, Tel: +0-11-52-664-687-22-07; E-mail: jorgitoparedesvieyra@hotmail.com

Rec Date: Nov 17, 2014; Acc Date: Dec 12, 2014; Pub Date: Dec 16, 2014

Copyright: $\odot 2015$ Vieyra JP et al., This is an open-access article distributed under the terms of the Creative Commons Attribution License, which permits unrestricted use, distribution, and reproduction in any medium, provided the original author and source are credited.

\section{Abstract}

Objective: Was to identify which lubricant was the best separating medium for taking an impression for an endodontic post and to determine which could be completely and rapidly eliminated from the walls of the post space.

Materials and Methods: Sixty endodontically treated maxillary incisor teeth were used. They were divided into six groups, 10 teeth in each group. Each group used a different lubricant except group 6 which served as the control.

Results: All five experimental groups showed that the oil and grease of the lubricants were difficult to totally eliminate from the porous dentinal surface when washed with $2 \mathrm{cc}$ of $96 \%$ ethyl alcohol. A post space prepared with Gates Glidden drills results in many opened dentinal tubules. These were filled with impression material when lubricants of groups I and III were used.

The best results were obtained with groups 4 and 5 although some impression material remained in the deeper (middle) portion of the post space.

Conclusions: This study showed that urea peroxide and glycerin and liquid hand soap were the most effective lubricating agents and were easier to remove from the post space walls with 2cc of $96 \%$ ethyl alcohol as compared with lubricants composed of mineral oil, glycerin or Dura Lay separator.
\end{abstract}

Keywords: Root canal; Endopost; Post; Canal wall

\section{Introduction}

How best to restore teeth after root canal treatment has long been a subject of debate and remains controversial to this day. Before initiating treatment, the practitioner should carefully examine the tooth for caries and fracture. The tooth should be assessed for restorability, occlusal function and periodontal health, and issues such as biological width and crown-to-root ratio should be evaluated. If these factors are deemed satisfactory, the tooth can be included in the comprehensive treatment plan.

Recent studies have improved our understanding of the inherent difficulties in restoring endodontically treated teeth [1]. A root canal occupies the most central portion of the root and is surrounded by healthy dentin. Even in multi canal teeth, a successful result is expected if the following simple clinical principles are adhered to:

a. Know the morphology of the root being treated.

b. Whenever possible use straight roots that can easily accommodate a post.

c. Avoid excessive removal of root dentin.
The basic objective is to restore the tooth esthetically and functionally.

Knowing that pulpless teeth are generally weak and subject to fracture, the restoration must be designed to provide maximum strength and protection against fracture.

Review of the literature revealed the following functions of an endodontic post:

Provide retention for the final restoration

Replaces missing tooth structure

Does not give additional strength to the pulpless tooth

If designed properly, occlusal forces will be better distributed

Because of the wide variations encountered in restoring pulpless teeth a single restorative technique cannot be applied in all cases. A variety of methods can be used depending on existing conditions.

Sometimes endodontic treatment is performed through an existing crown. If the crown appears clinically acceptable, the Access opening should be examined for dental caries. Dental caries detector substances can assist in the evaluation, as can magnification. Absence of caries should be assured before the Access opening is restored. If caries is 
present, the first choice is to remove the crown and remove the caries. The restorative dentist should then remove the crown and the remaining caries as soon as posible to minimize the chances of contamination of the root canal system.

When a space is made for a post, the clinician must remove only a minimum amount of tooth structure from the canal walls [2]. Over enlargement can result in a perforation or in weaken the canal walls whereby a fracture may occur during cementation of a post or during mastication. Research involving teeth with cemented posts of varying diameters showed that teeth with thicker posts $(1.8 \mathrm{~mm})$ fracture more easily than those with thinner posts $(1.3 \mathrm{~mm})$ [3]. Clinically, it is difficult to enlarge a canal uniformly and judge precisely how much dentin has been removed and how much remains.

Therefore, it is recommended that a canal only be enlarged to obtain sufficient retention for the post and restoration. Standlee, Kurer and Cooney [4-6], suggested that post length has some bearing on post retention.Although length is needed for retention, a preparation for a long post can result in a perforation of the canal wall or affect the apical seal. Either situation predisposes the case to failure.

It is universally agreed that a cast post should be as long as practical while still maintaining an apical seal of $4-5 \mathrm{~mm}$ of gutta-percha [7]. Whenever possible, the length of the post should be equal to or exceed the length of the clinical crown [8].

Although commercial prefabricated posts are frequently used, a customized cast post and core is traditionally recommended for coronoradicular stabilization of endodontically treated teeth [9]. Chapman et al. [10] revealed a statistically significant increase in root fracture for three different post systems when a crown was cemented on a beveled preparation instead of a non-beveled preparation.

Sorensen and Martinoff [11] reviewed more than 6,000 cases of nine general dentists and retrospectively evaluated 1,273 endodontically treated teeth. They found that the fracture rate of teeth with cast posts and cores was greater than that in teeth crowned without posts. From this, one can infer that posts per se should be abandoned.

Review of the literature revealed the following considerations regarding the fitting and cementation of a post. It should fit passively and go easily to place but should resist rotation or rocking after it is seated. Before cementation of the post the canal must be cleansed of all debris and lubricants [12]. The surface of the post must also be cleaned and any remaining small nodules on the surface of the cast post removed. If not removed they can create a wedging action and cause a root fracture. Hydraulic forces exerted during post cementation must also be kept to a minimum.

Because cementation is critical, all cements should be mixed according to the manufacturers recommendations to ensure suitable compressive strength and adequate working time. The purpose of this study was to identify which lubricant was the best separating medium for taking an impression for an endodontic post and to determine which could be completely and rapidly eliminated from the walls of the post space.

\section{Materials and methods}

Sixty endodontically treated maxillary incisor teeth were used. They were divided into six groups, 10 teeth in each group. Each group used a different lubricant except group 6 which served as the control.
Group 1: $\quad$ Mineral Oil (Johnson \& Johnson, México D.F.)

Group 2: Anhydrous Glycerine (Whitehall-Robins de México S.A.)

Group 3: Dura Lay Separator (Dura Lay Mfg.Co. Worth, IL.)

Group 4: $\quad$ Urea Peroxide and Glycerine(Oral B de México S.A. de C.V.)

Group 5: Liquid hand soap (Colgate-Palmolive Co. New York, NY)

Group 6: No lubricant (control group)

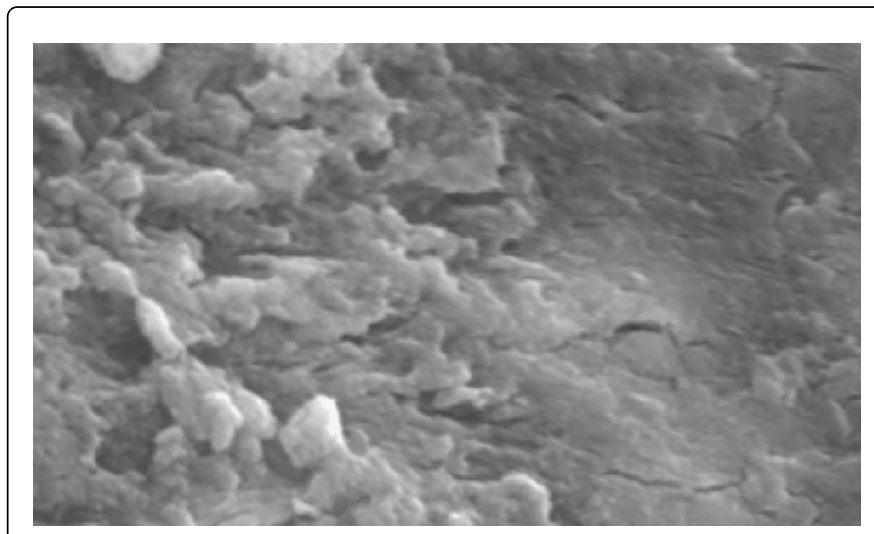

Figure 1: Impression material left on the canal walls when lubricants of groups 1 and 3 were used.

The 60 teeth were cleaned, shaped and obturated using a Step Back technique and Lateral condensation. After obturation, Gates Glidden drills \#3, \#4 and \#5, $25 \mathrm{~mm}$ length (Maillefer BALLAIGUES Switzerland), were used to stepping back $2 \mathrm{~mm}$ between each drill size to remove the guttapercha from the canal space. \# 40 Hedstrom file (Moyco/Union Broach, New York, NY) was used to remove any material that may have remained in the post space.

After the post space was prepared, the lubricant for each group was applied with a sterile \#35 paper cone and impressions of all 60 root canals were taken with red autopolimerizing acrylic resin (Dura Lay Mfg.Co.,Worth IL).

After the impressions were taken all the canals were washed with $2 \mathrm{cc}$ of $96 \%$ Ethyl Alcohol (FarmacéuticaMédica, Tijuana B.C.) and dried with \# 35 sterile paper cones. The acces cavities were sealed with a cotton pellet and zinc oxide and eugenol (LD Caulk Division Dentisply, Int.Inc.Millford,DE) .

A longitudinal cut was made into the root surface using a \#169 fissure bur and the root was split into two parts with a lecron spatula (Productosdentales Tovar, Mexico, D.F.).

The empty post space of each tooth was divided into 2 equal parts; the upper (cervical) and lower (middle) and examined under a light and Scanning electron microscope (Jeol JSM 5300).

\section{Results}

All five experimental groups showed that the oil and grease of the lubricants were difficult to totally eliminate from the porous dentinal surface when washed with $2 \mathrm{cc}$ of $96 \%$ ethil alcohol (Table 1). A post space prepared with Gates Glidden drills results in many opened 
Citation: Vieyra JP, Guardado JA, Enriquez JJ, Gomez MAZ (2015) Effect of Five Lubricants on Root Canal Walls during the Impression Phase of an Endodontic Post. Dentistry 5: 272. doi:10.4172/2161-1122.1000272

Page 3 of 5

dentinal tubules. These were filled with impression material when lubricants of groups I and III were used (Figure 1).

The best results were obtained with groups 4 and 5 although some impression material remained in the deeper (middle) portion of the post space (Table 1).

Conversely, groups 2 and 4 that were treated with anhydrous glycerine or Urea peroxide plus glycerine showed that remaining film left after taking the impression of the canal were almost eliminated when $2 \mathrm{cc}$ of alcohol was used to rinse the canal walls (Figure 2).

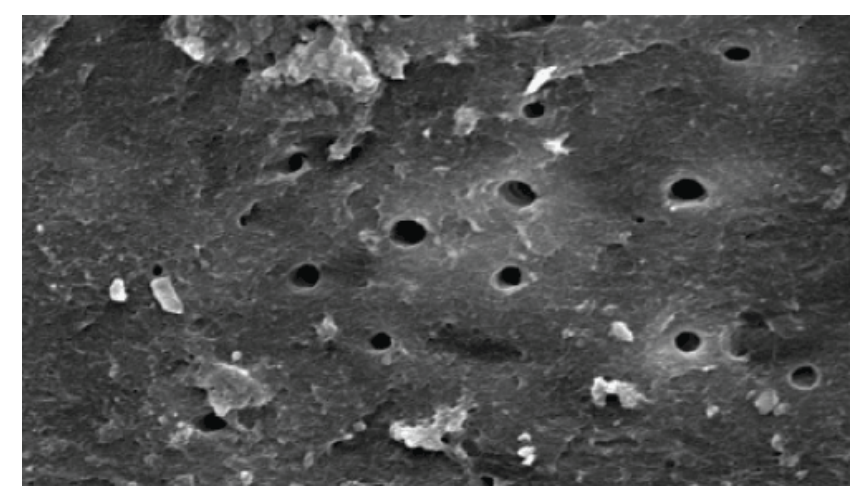

Figure 2: The best results were obtained with groups 4 and 5 although some impression material remained in the deeper (middle) portion of the post space.

The lubricant in group 5, was almost eliminated from the canal with alcohol (Figure 3). In group 6, where no lubricant was used, the impression material met some resistance on insertion and also on removal from the post space (Figure 4).

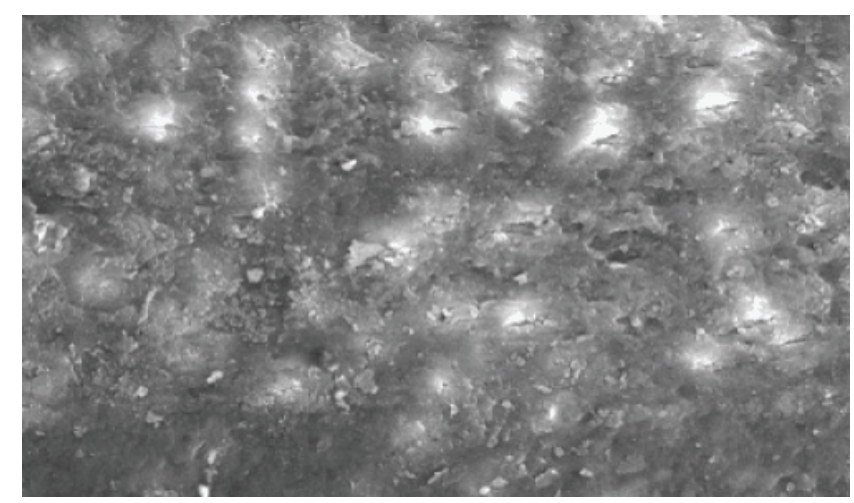

Figure 3: The lubricant in group 5, was almost eliminated from the canal with alcohol.

\section{Discussion}

Restoration of endodontically treated teeth restores the esthetics and function of such teeth and maintains the integrity of the endodontic treatment. In this study we evaluated lubricants used to coat canal walls before taking an impression of the post space [13].
This study showed that urea peroxide and glycerine and liquid hand soap were the most effective lubricants.

For maximum retention of the post the canal must be cleaned of all debris, impression material and lubricants before cementation. The post itself should also be cleaned to increase retention [14-16]. We recommend the use of alcohol before applying the lubricant and again before cementing the post.

Alcohol effectively removes urea peroxide and glycerine as well as liquid soap. Post retention can be reduced by the presence of lubricants and impression material on canal walls by interfering with adherence of the cementing medium to the dentin surface. Therefore, the operator must be very careful to remove both the lubricant and the impression material from the dentin wall with a solvent such as alcohol.

At times, calcium hydroxide may be used to temporarily fill the post space.In such instances thelubricants in groups 1 and 3 must be completely removed from the post space before placing calcium hydroxide because a mixture of calcium carbonate plus minerals will be formed. If a post is cemented within 12-24 hrs after placing calcium hydroxide, the mixture will interfere with cementation of the post.

We had the impression that the insertion and removal of the acrylic post was much easier when urea peroxide and glycerine (Group 4) was used as the lubricant. Using the group IV lubricant could also result in good post retention since the canal walls washed with $2 \mathrm{cc}$ of alcohol.

Since cementation is also a critical procedure the cement must be mixed according to the manufacturer's instructions to ensure proper compressive strength and working time.

Current oral rehabilitation concepts are oriented toward a tooth supported occlusion which offers physiologic benefits $[17,18]$. The intent of this procedure is to provide a solid base on which the restoration of the pulpless tooth can be prepared and retained. The post is a metallic intraradicular restoration which we make with the metal alloy silver - palladium.

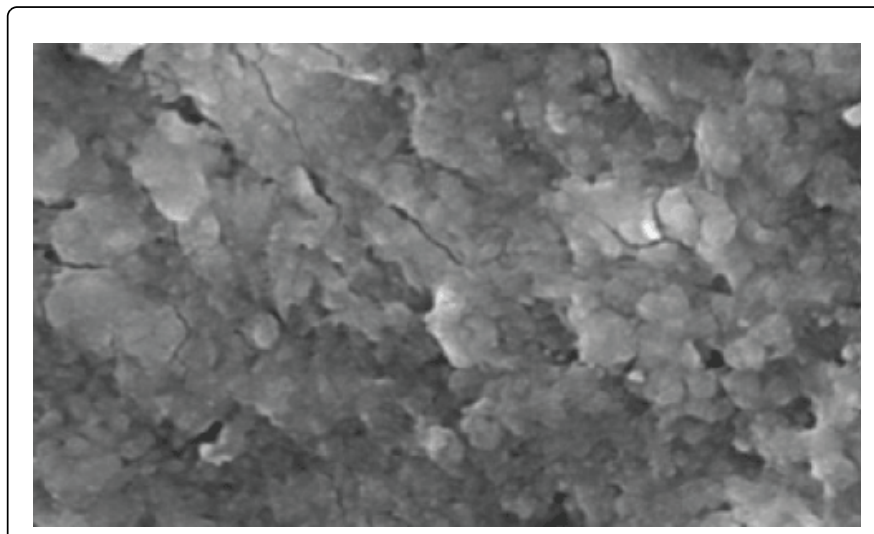

Figure 4: In group 6, where no lubricant was used, the impression material met some resistance on insertion and also on removal from the post space.

The impression material (group 6) had to be removed and reinserted several times to keep it from getting stuck in the post space. 


\begin{tabular}{|l|l|l|l|l|l|l|}
\hline Group & 1 & 2 & 3 & 4 & 5 & 6 \\
\hline Material lubricant & Mineral oil & Glycerine & Acrylic Lubricant & UreaPeroxide & Liquid & No Soap \\
\hline Middle third & 2 & 1 & 2 & 1 & 1 & 3 \\
\hline Cervical third & 1 & 1 & 1 & 0 & 0 & 2 \\
\hline \multicolumn{2}{|l}{ Note: 0- Absent, 1- Mild (one tooth), 2- Moderate (two teeth),3- Severe (more than three teeth) } \\
\hline
\end{tabular}

Table 1: Presence/Absence of impression material on canal walls after washing post space with alcohol.

Restoration of endodontically treated teeth does not follow any set pattern. Each tooth presents many different variables such as the amount and location of remaining coronal tooth structure [19]. Each case requires a skillful application of design based on the particular needs of each tooth.

Practitionersperformingendodontictreatmentshouldfollowtheseprin cipleswhenplanning and performing the restoration of endodontically treated teeth:

- Preserve coronal and radicular dentin.

- Avoid contamination of the root canal system.

- Restore the tooth immediately after root canal treatment, if possible.

- Use posts only when necessary to retain a core buildup.

- Restore teeth in a way that allows for future retreatment of the root canal system.

In most cases, the particular post system used is not as important as following the principles of adequate length, adequate resistance form, adequate strength to allow preservation of dentin, and anadequate ferrule. If these principles are followed, most post systems will perform well.

Everything we do as dentists is temporary with the exception of extractions. We perform procedures with the idea that they will be durable and longlasting, but none of them are permanent. Our treatment planning processes should reflect this reality [20-23].

\section{Conclusion}

The purpose for lubricating canal walls is to prevent impression material from sticking to them. This study showed that urea peroxide and glycerine and liquid hand soap were the most effective lubricating agents and were easier to remove from the post space walls with $2 \mathrm{cc}$ of $96 \%$ ethyl alcohol as compared with lubricants composed of mineral oil, glycerine or Dura Lay separator.

\section{References}

1. Johnson JK, Schwartz NL, Blackwell RT (1976) Evaluation and restoration of endodontically treated posterior teeth. J Am Dent Assoc 93: 597-605.

2. Helfer AR, Melnick S, Schilder H (1972) Determination of the moisture content of vital and pulpless teeth. Oral Surg Oral Med Oral Pathol 34: 661-670.

3. Trabert KC, Caput AA, Abou-Rass M (1978) Tooth fracture--a comparison of endodontic and restorative treatments. J Endod 4: 341-345.
4. Standlee JP, Caputo AA, Hanson EC (1978) Retention of endodontic dowels: effects of cement, dowel length, diameter, and design. J Prosthet Dent 39: 400-405.

5. Kurer HG, Combe EC, Grant AA (1977) Factors influencing the retention of dowels. J Prosthet Dent 38: 515-525.

6. Cooney JP, Caputo AA, Trabert KC (1986) Retention and stress distribution of tapered-end endodontic posts. J Prosthet Dent 55: 540-546.

7. Peters MC, Poort HW, Farah JW, Craig RG (1983) Stress analysis of a tooth restored with a post and core. J Dent Res 62: 760-763.

8. Abou-Rass M, Jann JM, Jobe D, Tsutsui F (1982) Preparation of space for posting: effect on thickness of canal walls and incidence of perforation in molars. J Am Dent Assoc 104: 834-837.

9. Ruemping DR, Lund MR, Schnell RJ (1979) Retention of dowels subjected to tensile and torsional forces. J Prosthet Dent 41: 159-162.

10. Chapman KW, Worley JL, von Fraunhofer JA (1985) Retention of prefabricated posts by cements and resins. J Prosthet Dent 54: 649-652.

11. Sorensen JA, Martinoff JT (1984) Intracoronal reinforcement and coronal coverage: a study of endodontically treated teeth. J Prosthet Dent 51: 780-784.

12. Hanson EC, Caputo AA (1974) Cementing mediums and retentive characteristics of dowels. J Prosthet Dent 32: 551-557.

13. Fredriksson M, Astbäck J, Pamenius M, Arvidson K (1998) A retrospective study of 236 patients with teeth restored by carbon fiberreinforced epoxy resin posts. J Prosthet Dent 80: 151-157.

14. Ferrari M, Vichi A, Mannocci F, Mason PN (2000) Retrospective study of the clinical performance of fiber posts. Am J Dent 13: 9B-13B.

15. Ferrari M, Vichi A, García-Godoy F (2000) Clinical evaluation of fiberreinforced epoxy resin posts and cast post and cores. Am J Dent 13: 15B-18B.

16. Aquilino SA, Caplan DJ (2002) Relationship between crown placement and the survival of endodontically treated teeth. J Prosthet Dent 87: 256-263.

17. Mannocci F, Bertelli E, Sherriff M, Watson TF, Ford TR (2002) Threeyear clinical comparison of survival of endodontically treated teeth restored with either full cast coverage or with direct composite restoration. J Prosthet Dent 88: 297-301.

18. Cheung GS, Chan TK (2003) Long-term survival of primary root canal treatment carried out in a dental teaching hospital. IntEndod J 36: 117-128.

19. Malferrari S, Monaco C, Scotti R (2003) Clinical evaluation of teeth restored with quartz fiber-reinforced epoxy resin posts. Int J Prosthodont 16: 39-44.

20. Iqbal MK, Johansson AA, Akeel RF, Bergenholtz A, Omar R (2003) A retrospective analysis of factors associated with the periapical status of restored, endodontically treated teeth. Int J Prosthodont 16: 31-38.

21. Lambjerg-Hansen H, Asmussen E (1997) Mechanical properties of endodontic posts. J Oral Rehabil 24: 882-887.

22. Gallo JR 3rd, Miller T, Xu X, Burgess JO (2002) In vitro evaluation of the retention of composite fiber and stainless steel posts. J Prosthodont 11: 25-29. 
Citation: Vieyra JP, Guardado JA, Enriquez JJ, Gomez MAZ (2015) Effect of Five Lubricants on Root Canal Walls during the Impression Phase of an Endodontic Post. Dentistry 5: 272. doi:10.4172/2161-1122.1000272

Page 5 of 5

23. Al-Wahadni A, Gutteridge DL (2002) An in vitro investigation into the effects of retained coronal dentine on the strength of a tooth restored with a cemented post and partial core restoration. Int Endod J 35: 913-918. 